\title{
COMPRENDER LA AGRICULTURA EN LOS ANDES PERUANOS: ECONOMÍA Y POLITICA EN LA COMUNIDAD DE YANQUE (CAYLLOMA, AREQUIPA)
}

\author{
Understanding Agriculture in Peruvian Andes: Economy and Politics \\ in the Community of Yanque (Caylloma, Arequipa)
}

MARIO SÁNCHEZ*

Fecha de recepción: 28 de diciembre de 2016 - Fecha de aprobación: 25 de abril de 2017

\section{Resumen}

Este artículo analiza la agricultura en el mundo andino a través del caso de la comunidad de Yanque, distrito de la provincia de Caylloma, departamento de Arequipa (Perú). La agricultura es su principal actividad social debido a la vital importancia colectiva de sus dimensiones económicas y políticas, que muestran cómo Yanque es una comunidad andina que, en el siglo XXI, continúa preservando la tradición de sus herencias culturales mientras se encuentra inserta en modernos cambios sociales que conllevan los dinámicos procesos de interrelación con sociedades urbanas y globales capitalistas.

Palabras clave: Andes, Agricultura, Economía, Política, Perú

\section{Abstract}

This paper analyzes agriculture in the andean world through the case of the community of Yanque, district of Caylloma province, department of Arequipa (Peru). Agriculture is the main social activity because of the vital collective importance of its economic and politics dimensions, that show how Yanque is an Andean community that, in the 21st century, continues to preserve the tradition of its cultural heritages while it is inserted in modern social changes that entail the dynamic processes of interrelation with urban and global capitalist societies.

Keywords: Andes, Agriculture, Economy, Politics, Peru

\footnotetext{
* Doctorante en Antropología con mención en Estudios Andinos, Pontificia Universidad Católica del Perú (PUCP). Profesor de Antropología Social, Universidad Peruana de Ciencias Aplicadas (UPC), Lima, Perú. El artículo está enmarcado en su investigación doctoral que estudia los usos de las nuevas TICs en una comunidad de los Andes peruanos. Correo-e: mario.sanchez.davila@gmail.com - pccumsan@upc.edu.pe
} 


\section{Comprender la agricultura} en los Andes peruanos: Economía y política en la comunidad de Yanque (Caylloma, Arequipa)

El presente artículo analiza el panorama actual de la agricultura en los Andes peruanos a través del caso de la comunidad de Yanque, donde la agricultura es la principal actividad social debido a la vital importancia colectiva de sus dimensiones económicas y políticas.

La comunidad de Yanque (3,417 msnm.) es uno de los dieciséis distritos que conforman la provincia de Caylloma, en el departamento de Arequipa (Perú), y cuya capital actual es el distrito de Chivay (3,635 msnm.). Yanque se encuentra ubicado a $150 \mathrm{~km}$. al noreste de la ciudad de Arequipa, a tres horas de camino en automóvil, por medio de una carretera asfaltada. La comunidad se inserta geográficamente dentro del valle del Colca y la cordillera interandina que divide las cuencas del Pacífico y del Atlántico, y tiene como límites geográficos a las comunidades de Ichupampa, Coporaque, Achoma y Chivay.

La comunidad de Yanque ha ocupado una privilegiada y estratégica posición política y económica dentro del valle del Colca: como sede central del poder del Señorío Collagua que controlaba la parte norte, este y sureste del valle, hacia los siglos $\mathrm{X}-\mathrm{XV}$; como centro de administración del Tahuantinsuyu Inca, en el valle, hacia los siglos XV-XVI; como capital de corregimiento y repartimiento del Virreynato Español, hacia los siglos XVI-XVIII; como capital de la provincia de Caylloma desde mediados del siglo XIX hasta las primeras décadas del siglo XX; y como espacio turístico donde se concentra la mayor cantidad de hoteles de todo el valle, desde finales del siglo $\mathrm{XX}$ hasta la actualidad.

Los resultados etnográficos presentados en este artículo son el fruto de los siguientes meses de corresidencia en el campo: julio-agosto, 2014; enero-febrero, 2015; julioagosto, 2015; y diciembre-febrero, 2017. La razón de esta elección se debe a que estos meses son cruciales para la agricultura (por ser temporada de lluvias, de cosecha y sembrío, y de rituales a la tierra, al agua y a las montañas) en los Andes peruanos.

\section{La economía en la comunidad de Yanque}

La agricultura de la comunidad de Yanque es de riego por inundación o gravedad, y es provista directamente por el agua de las lluvias y/o por los canales de las infraestructuras hidráulicas a través de turnos de riego. El nevado Waranqanti $(5,379 \mathrm{msnm}$.) es el canal principal de riego de la parcialidad de Yanque Hanansaya, cuyas tierras agrícolas se encuentran junto al pueblo, en la margen izquierda, mientras que el nevado Mismi (5,598 msnm.) lo es de la parcialidad de Yanque Hurinsaya, cuyas tierras agrícolas se encuentran frente al río, en la margen derecha. Vale mencionar, por un lado, que la profundidad del río Colca no ha permitido aprovechar sus aguas como bien hídrico de regadío; y, por otro lado, que las terrazas agrícolas artificiales $\mathrm{o}$ andenes - pertenecientes algunos al Periodo Intermedio Tardío y al Periodo Inca (Neira, 1961), y otros al Periodo Wari (Treacy, 1994) - están, en la actualidad, abandonados y en proceso de destrucción (Mujica Barreda y De la Vera Cruz, 2002), pues muchos comuneros no han heredado los conocimientos para hacer usufructo y mantenimiento de estas platafor- 
mas construidas para obtener tierras de cultivo a través de muros de piedra con el objetivo de edificar camellones para el sembrío y el riego por inundación o gravedad (Robles Mendoza, 2010 y 2008).

\subsection{El calendario agrícola: siembras, Iluvias, heladas y cosechas}

La agricultura yanqueña, como la de muchas otras comunidades andinas, se organiza en torno a una época de lluvia (enero-marzo), una época de helada (abril-mayo), una época de cosecha (junio-julio) y una época de siembra (agosto-diciembre). Si bien es cierto que enero marca el inicio de la época de lluvia, esta no ha empezado a caer, en Yanque, sino hasta mediados de febrero, en los últimos años. $Y$ es que según los comuneros de Yanque, una década atrás, aproximadamente, el clima era tan estable que, aseguran ellos, llovía constantemente desde finales de diciembre hasta marzo, pero, actualmente, quizás por el cambio climático y el calentamiento global, la caída de lluvias es tan inestable que desestructura varios sistemas de planificación agrícola y ganadera de la región. En el valle de Colca el agua es un recurso natural escaso, donde la temporada de lluvias es de corta duración y las heladas y sequías constituyen fuertes obstáculos para la agricultura (Benavides, 1988b).

En abril y mayo, ya no cae lluvia y empieza a caer el frío de la helada, aunque esta puede prolongarse hasta el mes de junio. En estos dos meses, no crece nada, ni siquiera el alfalfa, según el testimonio de los comuneros de Yanque. Y es que son los meses más fríos del año. En junio y julio se realizan las cosechas de la producción. En esta época, se realiza la siembra de maíz acom- pañada de la danza Q'amili y comparsas al ritmo de huaylillas. Es también en el mes de agosto cuando se empieza a regar. Por ejemplo, el Yaku Alcalde de Yanque Hurinsaya distribuye a cada usuario un riego por toma, de tres horas cada uno, y cada cuarenta y cinco días. Usualmente, esto ocurre a partir del 20 de agosto, luego de la limpieza de los canales de regadío, y llega hasta el 05 de septiembre, aproximadamente. Entre agosto y diciembre, se siembra maíz, cebada, quinua, habas mishca y papas mishca (primeros sembríos) para ser cosechadas a partir del mes de mayo, aunque varias unidades domésticas de Yanque desde la quincena de julio ya se encuentran preparando el arado para sembrar habas con el objetivo de cosecharlas en diciembre, pues las primeras cosechas, antes de que la oferta de la producción se vuelva masiva, tienen un alto precio de venta.

\subsection{Productos y mercados: autoconsumo, intercambio y compra-venta}

Entre el 2004 y el 2014, las campañas agrícolas de Yanque revelan, en orden decreciente de rendimiento (kilogramos por hectárea), un patrón en la producción de la comunidad: la alfalfa, la papa, la avena forrajera, el ajo, la cebada forrajera, la tuna, el olluco, la haba grano verde, la oca, la arveja grano verde, el manzano, el maíz amiláceo, la cebada grano, el trigo, la quinua y el maíz choclo (GRAA, 2014). Asimismo, es interesante constatar que, desde las reformas toledanas hasta la actualidad, los cultivos de maíz, papas, cebada, ocas, habas y quinua siguen siendo una constante (Manrique, 1986; Echeverría y Morales, 1952; Benavides, 1989; Mujica Barreda y De la Vera Cruz, 2002), pues han sido productos que pudieron adap- 
tarse a las limitantes condiciones geográfico-climáticas particulares de Yanque dentro del valle del Colca.

En Yanque, los productos agrícolas para el autoconsumo de las unidades domésticas son el maíz, el mote, la cancha, la haba y la quinua. Desde hace pocos años, a partir del auge internacional por los productos naturales, se ha comenzado a producir y a comercializar la quinua hacia el mercado nacional y el extranjero, cuyo precio chacra en nuevos soles por kilogramo es 5.74; llegando a costar hasta cinco veces más que otros productos agrícolas vendidos de la comunidad, tales como la alfalfa (0.07), la cebada forrajera (0.33), la avena forrajera (0.35), la haba grano verde (0.69), la papa (0.87), la tuna (1.22), la arveja grano verde (1.25), la oca (1.55), el manzano (1.60), la cebada grano (1.67), el olluco (1.74), el maíz amiláceo (1.89), el trigo (1.91), haba grano seco (1.98) y el ajo (4.30), de acuerdo con GRAA (2014).

Puesto que la comunidad no cuenta con mercado local, la producción agrícola de Yanque que no se encuentra destinada al autoconsumo se vende, diariamente, desde temprano por las mañanas y principalmente por mujeres, alrededor de las afueras del mercado de Chivay. Otra parte de la producción agrícola es comprada por acopiadores en la plaza de Yanque por las tardes. Así, pues, la producción agrícola no solamente se ha destinado al autoconsumo, sino también a generar los excedentes para el tributo (incaico, colonial y republicano), y actualmente para el mercado capitalista (Robles Mendoza, 2010 y 2008). Y es precisamente por el elevado costo de mano de obra que hace que muchos agricultores dejen de sembrar y se dediquen a rentar su mano de obra y/o a dedicarse a diversificar las formas de ingresos económicos. Actualmente, existen personas ajenas a Yanque que han adquirido en alquiler varios terrenos agrícolas de la comunidad para sembrar y cosechar, contratando mano de obra local y pagando alto precio por el jornal: "Antes era quince, veinte soles. Ahora están pagando, por ejemplo, por la siembra de ajo, cuarenta soles a las mujeres y tanto más a los hombres. Cobran carísimo, y ya no quieren venir con nosotros porque solo podemos pagarles menos soles" (Natalio Ocsa, 53 años, comunero dedicado a la agricultura y el turismo).

Pero, en la comunidad de Yanque, la organización de la producción, si bien se encuentra inserta en una economía capitalista (ya que el trabajo es asalariado), aún conserva elementos de una economía campesina. Es posible, entonces, aseverar que, en Yanque, la producción de la agricultura, allí donde es llevada acabo por miembros de la misma comunidad, se organiza bajo una lógica de reciprocidad asimétrica conocida como minka o waje-waje incompleto (Alberti y Mayer, 1974). Por ejemplo, por un día de jornal de siembra en la chacra, los peones - que además eran conocidos del propietario del terreno agrícola - recibían una retribución monetaria como cancelación de su trabajo, pero también comida y bebida en agradecimiento. Pero, allí donde la producción agrícola es controlada por agentes exógenos - como empresas - la relación con los peones solo se remite al pago monetario de su jornal. Lo mismo sucede con los niños y niñas. Cuando la chacra es propiedad de un comunero, los niños y niñas participan en la actividad agrícola, pero cuando el control lo ejercen las empresas, se restringe la contratación de mano de obra laboral agrícola a los 
mayores de edad, debido a la problemática legal. A ello habría que sumarle que la injerencia de muchos niños y niñas en la agricultura - a diferencia de lo que sucede en el turismo - ya no es vista como un aprendizaje para desempeñar en el futuro laboral, sino solo como ayuda hasta que ingresen al colegio (donde el tiempo que se le dedica a la agricultura se reduce considerablemente).

Por último, han desaparecido casi en su totalidad las ferias donde se realizaban trueques de los productos agrícolas locales por aquellos productos que no se sembraban ni cosechaban en las tierras de la comunidad; en la actualidad, solo se puede adquirir la producción agrícola foránea por medio de la compra y venta, cuando las ferias tienen lugar o, en su defecto, en las bodegas de Yanque o en el mercado de Chivay. Pero hay todavía algunas familias en Yanque que realizan pequeños trueques agrícolas dentro de la misma comunidad, como, por ejemplo, la familia Ocsa Checa, que cada cierto tiempo intercambia harina industrial por harina de casa con otras familias. $Y$ las hay también que intercambian productos de la zona por productos que solo se siembran y cosechan en otras latitudes. Se intercambia, por ejemplo, maíz, papas, habas y menestras secas por manzanas, zanahorias o verduras. Muchos comuneros recuerdan que hubo un tiempo en que las unidades domésticas no se alimentaban de arroz y azúcar, pues se comía lo que se producía en la comunidad, pero también recuerdan que se intercambiaba la sal de las minas de Caylloma y el chuño de Espinar (Cusco) por la cebada.

Si bien dentro de la comunidad de Yanque, el trueque ha pasado por un lento proceso de evanescencia durante la segunda mitad del siglo XX, muchos son los comuneros que señalan que desde hace una década, los intercambios de productos se han detenido considerablemente: "Sí, todavía sí [es vigente]. Pero antes era puro ayni no más. Así era antes, pero ahora es casi muy poco porque ya la gente no viene a hacer ayni solamente, quieren dinero. Pero hay otros, así de la edad de mí, que siempre está yendo, como a divertirse de ayudar al compadre, al ahijado o al amigo. Antes era así. Antes la yunta que hacíamos era también para turno, uno venía con su yunta así. Ahora no, cambió también eso. Ya no quieren ayni, ahora tienen que pagar, quieren que les paguen" (Gerardo Huaracha, 73 años, comunero dedicado a la agricultura, ganadería y turismo). Finalmente, podemos observar trueques de alimentos (panes por humitas) entre los agricultores y los pastores en la puna los días en que se realizan los trabajos, fiestas y rituales de escarbo de acequias en las parcialidades de Hurinsaya y Hanansaya.

\subsection{Más allá de lo agrícola: pluralidad de actividades}

La agricultura era la actividad económica central para la comunidad de Yanque hasta que comenzó a ser desplazada paulatinamente por una pluriactividad asalariada, fenómeno cuya tendencia se viene generalizando en otras comunidades andinas (Diez, 2012 y 2014). Así, en Yanque ya no se dedican solo a la agricultura, sino también a otras actividades y servicios complementarios, como el turismo, la artesanía, la ganadería, el transporte, la construcción, entre otros. 


\subsubsection{Turismo y artesanía}

A finales del siglo XX, el turismo aparece como una actividad productiva complementaria a la agricultura en la comunidad de Yanque, a partir de iniciativas de organizaciones, tales como DESCO (el Centro de Estudios y Promoción del Desarrollo) y, más tarde, AUTOCOLCA (la Autoridad Autónoma del Colca) y CID-AQP (el Centro de Innovación y Desarrollo de Arequipa). De esta manera, el turismo en Yanque empieza a estar controlado por tres tipos de ofertas y tres tipos de organizaciones.

En primer lugar, es importante destacar que existe una oferta turística que proviene de Arequipa, y que tiene una duración de un solo día, donde Yanque es una especie de no-lugar, porque aparece como un espacio de paso rumbo a los sitios turísticos hegemónicos (el cañón del Colca; la Cruz del Cóndor, en Cabanaconde; y el almuerzo en Chivay, donde también hay bares y discotecas), y luego hacia Puno y Cusco.

En segundo lugar, a las afueras de la comunidad, se construyeron hoteles de primera clase, tales como Las Casitas del Colca, el Colca Lodge, Tradición Colca o Eco Inn. Son hoteles que, hasta la actualidad, se encuentran enfocados en proporcionar al turista una estadía llena de relajación, en su mayoría, al interior del hotel (contando con gimnasios, restaurantes, bares, spas, miradores, biohuertos, zona de juegos y amplias áreas verdes). Son hoteles que, raramente, en sus paquetes de recorrido turístico, tienen contacto con la comunidad. Por ello es de comprender que aquellas actividades realizadas fuera de los límites del hotel, sean llevadas a cabo en el cañon del Colca, La Cruz del Cóndor (mirador de cóndores cerca de Cabanaconde), los baños termales de Chacapi, las colcas del puente Cervantes y el complejo arqueológico Uyo-Uyo, todos los sitios exentos de participación económica de la comunidad de Yanque.

En tercer lugar, en la comunidad, se incentivó a los comuneros a que hospeden a turistas. Esta oferta, que hoy se conoce como Turismo Rural Comunitario, se encuentra destinada primordial pero no exclusivamente a extranjeros, a quienes se les proporciona habitación (en rústicas casas hechas de adobe), alimentación (con productos y recetas de la comunidad) y guiado (no solo a los lugares hegemónicos de los hoteles de primera clase, sino también se trata de que los turistas acompañen a los comuneros a las chacras y a las estancias, que escuchen los mitos de la comunidad, etc.; tratan de adaptarse al día a día de los comuneros). En todo este panorama turístico, solo la oferta de los comuneros del Turismo Rural Comunitario ponen énfasis en la historia y la cultura de la comunidad de Yanque y del valle del Colca. Es importante señalar que existen otros circuitos turísticos que forman parte de la comunidad de Yanque - cuevas con pinturas rupestres, maquetas de la andenería de la comunidad, granjas de truchas, bosque de quenuales pero que no se muestran al público, público, porque el acceso a estos es accidentado y peligroso, y no existe una carretera ni infraestructura adecuada. A partir de estas tres grandes ofertas turísticas, existe en la comunidad de Yanque un fuerte aumento en la cantidad de hostales (quince, actualmente) que solo ofrecen habitación y alimentación. No obstante, hay que recordar que el turismo es una actividad complementaria de varios yanqueños que se avocan también a la agricultura y la ganadería, pues el turismo es una actividad estacionaria (enero-febrero y julio-agosto). 
No obstante, y siguiendo a Diez Hurtado (2014), la actividad turística en Yanque genera efectos bastantes limitados en el desarrollo local, pues, aunque mejora la infraestructura de los servicios en la comunidad, los ingresos se distribuyen solo entre las familias que logran insertarse en esta actividad. $Y$ es que solo las familias que más capitales detentan económico y/o político - pueden diversificar sus actividades productivas e insertarse de mejor manera en el turismo. Así, hay familias que, a partir del nacimiento del turismo como actividad económica en Yanque, se han ido posicionando en el poder. De hecho, existen cinco familias (Huaracha, Huaypuna, Ocsa-Checa, Mamani y Málaga1) que ofrecen turismo rural comunitario en Yanque. Aunque, a diferencia de las demás familias, Teodoro Huaypuna es el actual Presidente de la Comisión de Turismo de la comunidad, lo que ha implicado para él y su familia, de acuerdo con otros comuneros, concentrar los mayores y mejores beneficios de la misma actividad: desde el aprovechamiento de la demanda turística hasta los viajes de capacitación en el rubro. Así también, debido a que es Chivay la comunidad que centraliza el turismo en el valle del Colca, y al hecho de que no sean los mismos lugares los que deciden qué se debe valorar en la región, sino las mismas agencias de turismo que desarrollan propuestas turísticas que no toman en cuenta la población, es por eso que la participación comunal es escasa (Córdova, 2003; Poma y Aronés, 2011; Montoya, 2013).

Por otro lado, el creciente auge turístico en Yanque ha beneficiado indirectamente a otras personas de la comunidad. Por ejemplo, dentro de la comunidad de Yanque, la plaza constituye un espacio social central para sus habitantes, no solo por su ubicación geográfica, a la mitad del pueblo, sino también por su función comercial: aparte del Municipio de Yanque, la iglesia de la Inmaculada Concepción de Yanque y el museo de Yanque, administrado por la Universidad Católica Santa María de Arequipa, en la plaza se ha instalado un salón de belleza, dos restaurantes dedicados casi íntegramente a turistas, y siete bodegas donde se venden desde golosinas hasta productos de cocina y baño, siendo una de ellas la más concurrida por su oferta multiservicios que va desde el acceso a internet, fotocopias, escaneos, impresiones, cajeros automáticos, centro de llamados telefónicos (nacional e internacional), hasta recargas de teléfonos fijos y celulares. Antes había dos discotecas pero fueron clausuradas porque en una reunión de la junta comunal se acordó que ambas "rompían con la tradición". Y vemos claramente cómo esta representación de la modernidad - a diferencia de otros elementos no vetados en la comunidad, como la televisión, la fotocopiadora, la computadora, el Internet o el celular - atenta directamente con la construcción de un paisaje rural que - a diferencia de Chivay - se vende como tradicional, pues esta representación de tradición le es funcional, económicamente hablando, a varios yanqueños cuyas actividades - como el turismo o la artesanía - dependen de la misma.

La producción artesanal ha comenzado a ser una actividad altamente demandada no solo por mujeres sino también por hombres. Aunque la mayoría son mujeres, actualmente los hombres están tomando mayor interés por esta tarea, rompiendo brechas de género en dicha actividad. Así, los bordados y tejidos locales, con tonalidades y motivos tanto Cabana como Collaguas, desde hace unos años, han 
comenzado a ser demandados por un público turista nacional y extranjero; y es por eso que la producción y comercialización de chullos, guantes, medias, sombreros, chalinas, chompas e, incluso, warakas (hondas para lanzar piedras), entre muchas otras mercancías, hacen referencia a la identidad cultural de los pueblos del valle del Colca.

Actualmente, se ha instalado en la plaza de Yanque tres tiendas de mercancías artesanales producidas por mujeres y hombres de la comunidad. Así también, este saber-hacer es incentivado por instituciones públicas como la municipalidad, que ofrece cursos gratuitos de bordado y tejido. Además, existe un taller de producción artesanal junto a la plaza de la comunidad llamado Sumac Ruak, dirigido por mujeres. Este negocio le permite a las artesanas asociadas y a las artesanas independientes tener un ingreso propio y una mayor independencia económica, pero también, gracias a los bordados, recuperar identidades culturales propias de sus comunidades, posibilitando así que las mujeres aporten todavía más a la economía doméstica (lo hacen indirectamente con la provision y el control de alimentos desde la cocina), que no estén circunscritas únicamente a la casa y la chacra, y que tengan una mayor participación en la inversión monetaria en el estudio de sus hijos en la ciudad de Arequipa. Ciertamente, son las mujeres adultas las que han aprovechado su saber-hacer, aprendido cuando eran niñas, para insertarse en una economía capitalista. $Y$ aunque hay niñas que actualmente están aprendiendo sobre artesanía - ya sea en casa y/o en la municipalidad - estas son muy pocas, ya que tanto madres como hijas desean que estas salgan del pueblo para estudiar en la ciudad de Arequipa.
Pero también se puede ver cómo se venden estas mercancías todos los días en la plaza de Yanque a los turistas, desde hace cinco años aproximadamente. De lunes a domingo, de seis a ocho de la mañana, llegan buses turísticos a Yanque, y la plaza de la comunidad se convierte en una oportunidad de ganancia económica para los locales: vestidas con trajes Cabana y Collagua, unas mujeres venden tejidos, bordados y artesanías sobre el piso de la plaza y unas pocas lo hacen dentro en tres locales de la misma plaza. Y es posible rescatar la existencia de una lógica colectivista en el acceso a los mejores puntos comerciales de la plaza: todas las mujeres en la plaza rotan diariamente de sitio, porque hay zonas de la misma donde los buses desembarcan y los turistas compran más. Entonces, para evitar que siempre le compren a una misma comunera, se rotan el espacio de la plaza para ofertar sus productos y no concentrar, así, el poder de venta siempre en una sola mujer. Otras mujeres ofrecen fotografiarse junto a sus llamas, alpacas y cóndores; otras pocas, en una carretilla en una de las esquinas de la plaza, venden desayuno a los locales; mientras que niños y niñas de primaria y secundaria, en el centro de la plaza, alrededor de la pileta, antes de pedir una contribución económica a sus espectadores, salen a bailar el Wititi ${ }^{2}$, una danza presente en muchos distritos del valle del Colca, aunque en Yanque adquiere un propio estilo performativo, desde la vestimenta hasta el baile (según yanqueños de mayor edad, el Wititi, donde los hombres usan faldas y antifaces coloridos, tenía una doble función: por un lado, como una danza para sacar a las mujeres de sus casas con engaños y sin que sus padres se percataran de ello; $y$, por el otro, como una danza para confundir a los enemigos en batalla). 


\subsubsection{Ganadería, transporte y construcción}

En Yanque, la ganadería es una actividad cada vez más escasa. Como otros distritos, la comunidad de Yanque cuenta con estancias (también llamadas capillas o anexos) en las zonas altas de la puna dedicadas exclusivamente al pastoreo de alpacas, llamas y ovinos; y a las cuales los comuneros de las zonas bajas acceden a través de relaciones exogámicas con parientes residentes en estos pisos ecológicos (de entre $3,800 \mathrm{msnm}$. hasta $6,025 \mathrm{msnm}$.), intercambiando productos, servicios y/o dinero con los mismos por el cuidado del ganado (Valderrama, 2012). Sin embargo, el problema del abigeato (el robo de tropas de ganado) por las noches, la distancia con respecto a la comunidad, la demanda exclusiva de vigilancia y alimentación de las llamas y las alpacas en la puna, las problemáticas condiciones climáticas (lluvia y nieve) y la poca tenencia de animales, entre otros factores de corte económico, ya no permiten más que los yanqueños se dediquen solamente a ser ganaderos. Actualmente, hay solo unos pocos en la comunidad que han resistido y continúan siendo pastores de altura. Hay quienes se dedican a la crianza de vacas dentro de la misma comunidad, obteniendo leche y queso para el autoconsumo; pero hay también quienes se dedican al pastoreo de llamas y alpacas en la puna, donde no crecen ya productos agrícolas, y donde el pasto de la zona alta es el alimento central del ganado, por lo que los pastores se ven forzados a trasladar a los animales de lugar en lugar.

Hasta mediados del siglo $\mathrm{XX}$, ser pastor de llamas y alpacas era una actividad rentable en Yanque, pues se obtenía cantidades de carne y se trasquilaba la lana, y estas eran llevadas en camiones desde las estancias. Es por eso que los comuneros que se dedicaban solo a esta actividad tenían grandes cantidades de ganado (alrededor de doscientos animales, entre hembras y machos). $Y$ es que cuando se tiene una fuerte cantidad de ganado (desde cincuenta cabezas en adelante), la ganadería de puna se vuelve una actividad rentable, porque la venta de la carne y la lana generan ingresos; pero la ganadería dentro del espacio comunal también es una fuente de ingresos, porque, los vacunos dan leche, queso y mantequilla, y los toros se alquilan como arado. Sin embargo, cuando se tiene una baja cantidad de ganado, se complementa con la siembra y cosecha agrícola. Asimismo, la ganadería como actividad complementaria a la agricultura era altamente valorada porque tenía más recompensas y menos riesgos, pues las condiciones climáticas adversas podían destruir los productos agrícolas, mientras que el ganado de puna únicamente necesita resistir a las épocas de lluvia y nieve, pues a la época de helada los animales llegan con bastante lana, lo que les permite cubrir su cuerpo y resistir el frío.

Finalmente, hay quienes han diversificado sus fuentes de ingresos económicos a partir de su inserción en los servicios asalariados del transporte (trasladando pasajeros entre Chivay y Yanque) y en la construcción (empleando su mano de obra para proyectos de edificación en la comunidad). Por ejemplo, muchos comuneros fueron contratados por la municipalidad del distrito para realizar los trabajos del proyecto de mejora del sistema de alcantarillado de Yanque. Por último, hay quienes han abandonado por entero la actividad agrícola, por el alto esfuerzo físico que amerita, los riesgos climáticos y la baja rentabilidad para dedicarse a complementar sus medios de adquisición económica con las nuevas actividades y servicios. 


\subsubsection{Jóvenes y actividades asalariadas}

Tal como ha sucedido en otras comunidades del valle del Colca que han diversificado sus ingresos económicos a partir de nuevas actividades y servicios, en Yanque, los agricultores y pastores afirman que la rutina familiar agropecuaria es muy pesada, sin considerar además los bajos precios de la comercialización de su producción minorista. Es por eso que adolescentes y jóvenes yanqueños, hijos de viejos agricultores y pastores de la comunidad, recuerdan el fuerte compromiso que requerían las obligatorias rutinas de involucramiento productivo (regar y cosechar en la chacra; alimentar, dar de beber y sacar leche de las vacas, por ejemplo). A esta fuerte responsabilidad laboral se le agregan la baja productividad agrícola, las adversas condiciones climáticas y la poca rentabilidad agrícola, lo que nos permite comprender porqué muchos adolescentes y jóvenes de Yanque no quieren dedicarse a las tradicionales actividades agropecuarias y, mas bien, deciden insertarse en nuevas actividades y servicios. Pero se entiende, también, porqué actualmente los hijos de agricultores y pastores estudien o planeen estudiar en la ciudad de Arequipa, sea para regresar a la comunidad y gestionar actividades asalariadas no tradicionales (como turismo, administración, secretariado y computación, entre otras carreras técnicas y/o universitarias), o sea para quedarse a trabajar, volviendo solo para las fiestas de la comunidad; ocasionando este fenómeno migratorio contemporáneo un problema de nuevos trabajos asalariados para las generaciones más recientes. $Y$ es que tanto padres como los hijos quieren que estos estudien para ser profesionales y tener un salario. $Y$ por eso señalan que si los hijos ya no se van a dedicar a continuar la actividad agrícola, las tierras familiares, inevitablemente, tendrían que ser vendidas. Existen otras familias que han comenzado a invertir en la compra de terrenos y en la construcción de viviendas en los conos de la ciudad de Arequipa, donde sus hijos planean estudiar en un futuro cercano.

\section{La política en la comunidad de Yanque}

La actual comunidad de Yanque congrega cinco formas de autoridad política que permiten comprender los cambios y las continuidades de un distrito que cuenta con una economía comunal (que involucra actividades de producción agropecuaria donde el agua es un recurso natural público y la tierra es un recurso natural privado, pues, en general, si bien la propiedad agrícola en la comunidad de Yanque no se encuentra reconocida legalmente, sí está reconocida comunalmente, siendo la misma susceptible de ser comprada o vendida por los usuarios; pero dentro de un marco colectivo de gestión y protección, y donde los cargos de autoridad son obligatorios) inserta en una economía capitalista de mercado (que involucra no solamente actividades de mano de obra asalariada, sino también formas industriales de producción de bienes artesanales y servicios turísticos, donde el acceso a los recursos es tanto individual como familiar).

\subsection{Formas de autoridad}

La presencia de las cinco formas de autoridad política: Presidente de la Comisión de Regantes, Presidente de la Comunidad, Alcalde Municipal, Presidente de la Comisión de Turismo y Yaku Alcalde, revelan los distintos sistemas políticos que operan en Yanque. Por ello, con el fin de 
situar la vida política del distrito, se hace alusión a sus cinco autoridades más importantes, pues la vigencia de estos tipos de representación política nos permiten ver distintas formas de organización, y sus complejas interrelaciones dentro de la comunidad. Estas cinco formas de autoridad política, así como el posicionamiento de las familias de poder y la identidad mitológica de los yanqueños como Ucños mañay yaku, se vuelven cruciales para entender la jerarquía política de Yanque y las relaciones políticas al interior de la comunidad. Y recordemos, con Plaza y Francke (1981), que es en la dimensión comunal donde se gestionan los recursos naturales (el agua y la tierra) y los recursos sociales (la mano de obra); pero también que la comunidad combina funciones de regulación tanto económica como política con respecto al medio, a sus recursos y a sus miembros, dentro de un escenario organizacionalmente multiforme donde coexisten, interactúan y compiten asociaciones y actores diversos (Diez Hurtado, 2001).

\subsubsection{El Presidente de la Comisión de Regantes}

En la comunidad de Yanque, existen dos Comisiones de Regantes, una para Hanansaya y otra para Hurinsaya, como organizaciones representativas de todos los usuarios de agua con fines agrarios de los Sub Sectores de Riego de ambas parcialidades. Los usuarios de agua son todas aquellas personas naturales o jurídicas que cuentan con el derecho de usufructo de agua otorgado por la Autoridad Nacional del Agua (ANA, 2014). Todos los usuarios tienen el deber de pagar una tarifa de agua como contribución económica por metro cúbico del recurso hídrico utilizado en su actividad. El Consejo
Directivo de ambas Comisiones de Regantes se encuentra conformado por un presidente, un vicepresidente y cuatro vocales. Pero también por un tesorero, como parte del área de tarifas y cobranzas. No obstante, como parte de la estructura orgánica de la Comisión de Regantes, son importantes también las funciones del Vicepresidente y de los Vocales. La función del Vicepresidente es reemplazar al Presidente en caso de haber impedimento, licencia o ausencia temporal del último, ejerciendo sus atribuciones y responsabilidades. La función de los vocales es llevar al día los Libros de Actas de la Asamblea; tener al día los Padrones de Usuarios, los registros y el inventario del patrimonio institucional; y tener al día y vigilar que los libros y documentos de contabilidad estén archivados.

El Presidente de la Comisión de Regantes es, formalmente, el mediador entre el Ministerio y la comunidad con respecto a temas agrícolas. Es el representante legal de la Comisión de Usuarios del Sub Sector de Riego de cada parcialidad ante las reuniones del Comité de Coordinación del Distrito de Riego, con poder de votación representativa de Hanansaya o Hurinsaya, pero también ante los órganos jurisdiccionales del Poder Judicial. Las funciones del Presidente consisten, por ello, en A). Convocar y presidir las sesiones de asambleas de la Comisión de Usuarios y del Consejo Directivo; y B). Cumplir y hacer cumplir los acuerdos comunales, presentando los informes trimestrales de trabajo, proponiendo las medidas correctivas, suscribiendo las actas de las sesiones y respondiendo solidariamente frente a los usuarios por el daño, abuso de facultades o negligencia grave.

Los usuarios y la Comisión de Regantes se reúnen en una Asamblea. La reunión ordinaria 
tiene como objetivo aprobar todos los Estados Financieros y el programa anual de trabajo y presupuesto del periodo próximo. Por ejemplo, días previos al escarbo de acequia en el nevado sagrado Mismi, la Comisión de Regantes de Yanque Hurinsaya se reúne desde los primeros rayos del sol a debatir y coordinar compromisos para la realización comunal de asuntos agrícolas y rituales (como la gestión respecto de la mano de la obra para el mantenimiento de canales de regadío de Yanque Hurinsaya del 01 al 04 de agosto en el canal Mismi; el 12 de agosto en los canales laterales de la campiña; y el 05 de septiembre en el canal Sifón y el canal Colloni), balances económicos de la caja chica, renovación de alquiler de las tierras comunales, exposición de las rencillas entre usuarios, entre otras cosas, para terminar sellando, lo que se ha pactado colectivamente, tinkando (asperjando y bebiendo un líquido con una divinidad quechua para demostrar respeto, pedir permiso, dar gracias y/o solicitar protección) con gaseosa. Por otro lado, la reunión extraordinaria tiene como objetivo dar conformidad a la cuota propuesta por el Consejo Directivo; aprobar y autorizar la gestión de préstamos y su financiación; aprobar y modificar el Estatuto; acordar la remoción de miembros del Consejo Directivo; establecer la responsabilidad administrativa del Consejo Directivo; y elegir los miembros del Comité Electoral.

\subsubsection{El Presidente de la Comunidad}

En Yanque, a partir de la Ley General de Comunidades Campesinas promulgada en 1987, existen dos Presidentes de la Comunidad: uno para la parcialidad de Hanansaya y otro para la parcialidad de Hurinsaya. En tanto cargo rotativo, es obligación de todo comunero activo que reside en el distrito y que es elegido por el pueblo en elecciones comunales para representar a cada parcialidad, cumplir con la función de realizar cambios en beneficio del pueblo de acuerdo con el estatuto de la Comunidad Campesina, y con la función de administrar los recursos económicos de la comunidad. En ese sentido, si la Comisión de Regantes rige sobre el agua, la Comunidad Campesina rige sobre la tierra. De esta manera, el Presidente de la Comunidad asiste a todas las asambleas con el objetivo de comprender las necesidades comunales con relación a la actividad agropecuaria, pero también sobre otros proyectos productivos, como la actividad turística, que impliquen el desarrollo de relaciones con entidades exógenas (hacia afuera de la comunidad de Yanque), desde la búsqueda de presupuesto económico en el Municipio y en el Estado hasta la asesoría legal sobre temas medioambientales.

\subsubsection{El Alcalde Municipal}

Si el Presidente de la Comunidad es representante de la comunidad ante las instituciones exógenas, el Alcalde Municipal es el elegido por el pueblo como intermediario entre la comunidad y el Estado y otros contextos oficiales. No obstante, muchos alcaldes municipales no han sido usuarios ni comuneros activos dentro de ambas parcialidades; por el contrario, solo aquellos que tienen escolaridad completa y otros títulos educativos pueden acceder al cargo de Alcalde Municipal. Y es precisamente por su identidad social de no ser un miembro activo dentro de las actividades productivas yanqueñas, que el Alcalde Municipal es percibido como liminal. $\mathrm{Y}$, por eso, se comprende 
que la relación entre la municipalidad y la comunidad sea una de contrapartida. Por ejemplo, las obras de construcción se realizan con la mano de obra que dispone la Comisión de Regantes y con el material que brinda el Municipio. En una ocasión, se derrumbó un canal de regadío y, para repararlo, la Comisión de Regantes otorgó mano de obra y el Municipio concedió herramientas, cemento y movilización. Por eso, la comunidad de Yanque también se encuentra inserta, aunque en menor medida de dependencia, en una economía estatal representada por el cargo político electivo de Alcalde Municipal. Sin embargo, como sucede con el resto de los cargos políticos, aparecen alrededor de este reclamos de falta de compromisos y colaboraciones, aunque habría que añadir que sobre este específico cargo político han proliferado el deterioro y la pérdida de la legitimidad del gobierno local sobre la representación de intereses comunales (Diez Hurtado, 2001); pero además habría que señalar que, para muchos comuneros, el cargo de Alcalde Municipal constituye el cargo político más difícil de fiscalizar, pues, a diferencia del resto, se ejerce muchas veces fuera de la comunidad.

\subsubsection{El Presidente de la Comisión de Turismo}

Desde finales del siglo $\mathrm{XX}$, el mejoramiento de las vías de comunicación, entre otros procesos de urbanización, originó la desarticulación de las actividades tradicionales, como el trueque interzonal, $y$, a la vez introdujo actividades modernas, como el turismo. Es en este contexto contemporáneo en el que Yanque se posiciona, actualmente como el lugar donde se concentra la mayor cantidad y calidad de hoteles de todo el valle del Colca. El turismo, como una actividad económica complementaria de la agricultura, deja de ser una práctica comunal, y se vuelve, mas bien, una práctica familiar e incluso individual. $Y$ aparece, así, un nuevo cargo para gestionar la actividad turística al interior de la misma comunidad. El Presidente de la Comisión de Turismo tiene como función facilitar el acceso de las familias y/o individuos a cubrir la demanda turística de forma rotativa o equitativa, pero también tiene como función buscar alianzas con instituciones exógenas, tales como agencias, organizaciones no gubernamentales e incluso estatales, con el fin de conseguir apoyo en materia de presupuesto y capacitación.

\subsubsection{El Yaku Alcalde y otras autoridades rituales}

Aunque hubo autoridades políticas prehispánicas de administración pública, tales como el Aqorasi (el anciano venerable), el Llaqtakamayoq (la cabeza de pueblos) o el Tukuy Rikuq (aquel que ve y escucha todo, o aquel que es ojos y oídos del pueblo), la figura del Varayoq (aquel que sostiene la vara), se crea en la segunda mitad del siglo XVI como un cargo cívico-religioso con fines de administración pública colonial (Barrionuevo, 1971). Y fue rápidamente aceptado por la población local indígena, como sucedió con los caciques, no solo porque se anexó al sistema de autoridades hispanas a reconocibles y respetadas autoridades aristocráticas andinas, sino también porque la sociedad indígena había tenido experiencias similares con gobernantes impuestos por el Estado incaico (Ráez, 2001).

Ciertamente, los Varayoq ya no cuidan que los indios hagan sus testamentos, no velan por 
los huérfanos, no visitan hospitales, no controlan el funcionamiento de los mercados, no vigilan las sementeras ni los ganados, no aderezan los caminos, las iglesias, los tambos ni los puentes, ni cuidan las chacras de los andenes (Barrionuevo, 1971). Indudablemente, los Varayoq ya no siguen subordinados al poder local de la hacienda ni prestando apoyo a las autoridades políticas impuestas por el Estado (Ráez, 2001). Así, pues, aunque el cargo de la figura de Varayoq haya perdido muchas de sus funciones coloniales y republicanas, continuó persistiendo, en tanto cargo cívico-religioso, como Juez de Aguas desde 1902 hasta 1969, cuando, con la Nueva Ley de Aguas № 17752 de la Reforma Agraria de Juan Velasco Alvarado, se oficializan las Comisiones de Regantes y se reconoce estatalmente la figura del Regidor de Aguas, o también llamado en contextos locales, Varayoq, Envarado, Taita Alcalde, Alcalde de Aguas o Yaku Alcalde, y como miembro activo del organigrama de las Comisiones de Usuarios hasta la actualidad.

Dentro del organigrama estructural de las Comisiones de Usuarios, el Yaku Alcalde, con todas las responsabilidades que tiene a cargo y desempeña, se encuentra anexado formalmente como parte del área técnica de operaciones y mantenimiento. Aunque, como señalaban Valderrama y Escalante (1988), todavía hoy, y solo para el Ministerio de Agricultura, el Presidente de la Comisión de Regantes encabeza la estructura jerárquica. Pero, en la práctica, es el Yaku Alcalde el que tiene el mando en la administración del agua. Así, bajo la estructura formal (la que se muestra hacia afuera) subyacen las autoridades tradicionales que dirigen el manejo del agua (que es el válido al interior de la comunidad). $Y$ aunque, a nivel oficial del Estado, la figura del Yaku Alcalde solamente tenga impor- tancia cívica (en tanto gestor técnico del agua), a nivel local de la comunidad, la figura del Yaku Alcalde también tiene importancia religiosa. Podemos ver, así, cómo el Yaku Alcalde se desenvuelve en el ámbito formal (autoridades y funciones definidas por una estructura legal de gobierno estatal), el informal (autoridades y funciones definidas por patrones locales de prestigio personal), el interno (códigos culturales de organización específicos de cada autoridad local) y el externo (capacidad de relacionarse con instancias exógenas), al igual que otras autoridades locales dentro de escenarios rurales (Damonte, 2000; Ráez, 2002). Pero la figura del Yaku Alcalde no solo es voluntaria, muchas veces es también obligatoria, pues, debido a la gran inversión en tiempo y dinero, los comuneros se disputan no por pasar el cargo, sino por no pasarlo (González Aguilar, 2016). Por eso los cargos cívico-religiosos son de duración limitada y rotativos, tienen funciones específicas, trajes habituales y atributos determinados, y están jerarquizados entre sí (Diez Hurtado, 2005).

Desde el punto de vista productivo, el Yaku Alcalde es el facultado para regir, a través de un conjunto de normas reglamentarias, el acceso comunal de los usuarios al agua. De esta manera, de acuerdo al Manual de Organización y Funciones de la Comisión de Usuarios de Yanque Hurinsaya (2015), el Yaku Alcalde se encarga, principalmente, de A). Llevar el registro de apertura y el cierre de compuertas, así como de los caudales medidos en las tomas a su cargo formulando su parte diario; B). Regular las compuertas de las tomas de los canales de derivación a su cargo, según el rol de distribución; C). Controlar el caudal del agua que discurre por las tomas a su cargo; D). Vigilar que las compuertas de las tomas a su cargo no sean 
operadas por personas ajenas; E). Efectuar labores de limpieza de las tomas de captación a su cargo e informar cuando estas labores requieran de la participación de los usuarios; F). Mantener en buen estado los precintos y demás sistemas de seguridad de las tomas; G). Efectuar el reparto diario de agua de acuerdo al rol de riego de distribución que establezca el Jefe de Sector o Sub Sector de Riego; H). Elaborar los partes diarios de distribución de agua por usuario y por predio; I). Controlar las limpiezas y reparaciones de los canales, tomas, drenes y caminos de vigilancia de su zona de trabajo, así como de las reparaciones de las obras de conservación y control de inundaciones; J). Informar sobre las infracciones en la distribución y aprovechamiento del agua, así como de los problemas de manejo de agua y del suelo; K). Colaborar en la distribución y recepción de solicitudes de plan de cultivos para plan de riegos; L). Informar a los usuarios sobre eventuales cortes de agua, ya sea por limpieza del canal principal, por alguna obra de canalización $u$ otro motivo.

Desde el punto de vista ritual, el Yaku Alcalde es el facultado para acercar a los comuneros (lo humano) con el agua, la tierra y las montañas (lo divino). Precisamente por ello no es coincidencia que la palabra quechua Yaku se utilice para denominar al agua en tiempos profanos, mientras que la palabra aymara Mallku, aunque signifique antepasado, se utilice para denominar al agua en tiempos sagrados.

En la comunidad de Yanque, existen cuatro Yaku Alcaldes, dos para la parcialidad de Hanansaya (con propiedad de la varas de Waranqanti y Ticlla) y dos para la parcialidad de Hurinsaya (con propiedad de las varas de Mismi y Sifón). $Y$ todo comunero que tenga más de cinco topos de tierra tiene la obligación de pasar por el cargo de Yaku Alcalde si es que este es solicitado por el resto de usuarios. Esta obligación de compromiso y colaboración exime al Yaku Alcalde de recibir un pago formal, aunque sí se le brinda una ayuda simbólica por parte de los miembros de la Comisión de Regantes (para los gastos que aparecen en el ejercicio de sus funciones como gestor del recurso hidráulico) y una retribución simbólica por parte de los demás comuneros (por los gastos que requiere el desempeño de sus funciones como responsable del ritual y organizador de la fiesta).

Y es que si el Yaku Alcalde es el sujeto intermediario entre lo profano y lo sagrado, la vara es el objeto intermediario entre la comunidad y el Tata Mallku y la Mama Pacha. Por ello es que la vara tiene nombre (bautizadas como Juan de la Cruz y Presentación, en Yanque Hurinsaya; y como Tomás y Guardia Civil, en Yanque Hanansaya) ${ }^{3}$, tiene cuerpo (una vez sahumada para limpiarla, es vestida para que no sienta el frío de la montaña y adornada con wayta, planta que también adorna los sombreros de los comuneros más importantes), y tiene condición (guardada en un altar al interior de la casa): en definitiva, tiene vida propia. Tanto así es la relevancia social de la vara en Yanque que, después del ascenso al Mismi para hacer el pagachi el 31 de diciembre de cada año, las autoridades económicas, políticas y religiosas se reunen en la casa del Yaku Alcalde para llevar a acabo el tradicional varamaya o limpieza de la vara (con alcohol).

La vara es una insignia de mando precolombina, aunque a partir del periodo colonial, con el cargo de Varayoq, la vara, hecha de madera y metal, posee símbolos sincréticos religiosos tanto católicos (el crucifijo) como quechuas 
(el sol, la luna, las plantas y los vegetales, así como también figuras geométricas). Por eso, las varas son bendecidas en la iglesia por los curas, reconociendo el poder que han detentado por siglos y marcando el inicio del año de regiduría, sin posibilidad de reelección del Yaku Alcalde. Y, por eso, la vara como símbolo de autoridad local (Arguedas, 1985; Valderrama y Escalante, 1988; Ramírez León, 2014), posiciona al Varayoc (aquel que sostiene la vara) no solo como Yaku Alcalde (Alcalde o Regidor de Aguas), sino también como el representante comunal en contextos rituales: no solo comunica a la comunidad con la naturaleza a partir de la productividad, sino también a partir de lo ritual, actualizando, con ayuda de un Kamachikuq Yana (el especialista), de un Rikuy (el servidor del Yaku Alcalde) y de un Kamachikusqa (el ayudante del Yana), las costumbres mitológicas y religiosas andinas, constituyendo así la memoria viva que hace posible la persistencia de las formas y los contenidos de los conocimientos ceremoniales.

\subsection{Familias de poder y tenencia de tierras}

En la comunidad de Yanque, el agua es un recurso natural público y la tierra es un recurso natural privado, pues, si bien la propiedad agrícola en Yanque no se encuentra reconocida legalmente, sí está reconocida comunalmente (siendo esta susceptible de ser comprada o vendida por los usuarios), y, por ello, el usufructo de las tierras se encuentra dentro de un marco colectivo de gestión y protección.

\subsubsection{Etno-clasificación de usuarios y concentración de topeaje en el siglo XXI}

Yanque, como otros distritos, tiene tierras de usufructo comunal, pero es el único que posee territorios productivos en ambas márgenes del río Colca, con una aproximada extensión territorial de $1,108.58 \mathrm{~km} 2$ (INEI, 2011) que incluye a sus dos parcialidades (o sayas) con sus respectivos territorios agrícolas: Hanansaya (con aproximadamente 2,000 topos) y Hurinsaya (con aproximadamente 650 topos), datos que pertenecen, respectivamente, al Padrón General de la Comisión de Usuarios de Yanque Hanansaya y Hurinsaya (2013); una cifra similar - Hanansaya (790 hectáreas) y Hurinsaya (233 hectáreas) - se encuentra en el Cuadro de Valores de Retribución Económica: tarifa por Uso de Infraestructura Hidráulica Menor de la Junta de Usuarios del Valle del Colca (ANA, 2014). $Y$ recordemos que el topo, como unidad de medida de la superficie agraria, equivale a 1/3 de hectárea (3,333 m2), y consistió en una categoría andina de extensión territorial (Rostworowski, 1981) utilizada en la zona de Arequipa y Caylloma durante el Virreynato Español, y todavía empleada en muchas comunidades del valle del Colca en el siglo XXI; aunque Benavides (1988) señala que el topo colonial corresponde a 3,496 m2.

Los registros del Padrón General de Usuarios de las parcialidades de Yanque Hurinsaya y Yanque Hanansaya (2013) revelan que los apellidos Checa, Huaracha, Inca, Llaza, Mamani, Rivera y Vilcazán no solo son los más recurrentes, sino que además pertenecen a quienes concentran la mayor cantidad de topeaje (quince topos en promedio por persona). Dicha cifra es importante si se toma en consideración que la mayoría de los usua- 
rios no supera los cinco topos de tenencia de tierras agrícolas, donde, según la etno-clasificación de usuarios a partir de la tenencia de tierras, los que poseen entre uno y cinco topos son minoristas, los que poseen entre cinco y ocho topos son medianos, y los que poseen entre ocho a veinte topos son mayoristas.

\subsubsection{Visitas y censos: distribución y control de tierras del siglo XVI-XX}

Estos datos de campo también son importantes si recordamos que, siguiendo a Benavides (1988), la estratificación socio-económica jerarquizada en el valle del Colca ha subsistido desde el siglo XVI hasta el siglo $\mathrm{XX}$, y fue evidenciable en el control de la propiedad, el uso de tierras agropecuarias, la mano de obra campesina y los principales cargos políticos por parte de grupos familiares de autoridad local. De este modo, en el Censo Parroquial de Yanque de 1899, se evidencia que las familias Rivera, Málaga y Huerta eran las más importantes del distrito de Yanque, que provenían de la ciudad de Arequipa y que se encontraban emparentados entre sí, siendo el sector dominante de la comunidad; y que fueron esos mismos grupos de poder (Fonseca, 1988) los que concentraron el control político-económico de Yanque hasta pasada la mitad del siglo XX (Benavides, 1988), cuando los habitantes de Yanque Hurinsaya y Yanque Hanansaya iniciaron el proceso de su reconocimiento legal y su empoderamiento político como Comunidades Campesinas, a partir de la Ley de Reforma Agraria (1969), promulgada por el gobierno de Juan Velasco Alvarado, aunque Yanque ya era una Comunidad Indígena desde el gobierno de Augusto B. Leguía, con la Constitución de 1920.
Asimismo, estos datos de campo son todavía más relevantes si tomamos en cuenta que tanto las visitas a Yanque-Collaguas Hanansaya (1591) y a Yanque-Collaguas Urinsaya (1591), publicadas en Pease (1977), como las visitas a Yanque-Collaguas Hanansaya (1615-1617) y a Yanque-Collaguas Urinsaya (1604), publicadas en Robinson (2006), revelan una marcada estratificación en la tenencia de tierras, concentrada en un minoritario número de miembros de familias privilegiadas, como los caciques, y mucho después, los gobernadores, alcaldes, jueces de paz, presidentes de asambleas comunales, quienes heredaron sus posesiones entre miembros directos de su clan familiar (de padres a hijos) a través de los siglos. Así, hacia 1591, la mayoría de los miembros de Yanque Hurinsaya poseía entre uno y cinco topos, mientras que una minoría concentraba una tenencia mayor a nueve topos. Cuatro siglos después, hacia 1981 (en Hurinsaya) y hacia 1982 (en Hanansaya), el patrón persistía (Benavides, 1988), así como hacia 1985 en ambas parcialidades (Valderrama y Escalante, 1986). Esa misma recurrencia es evidenciable también, hacia el 2008, en ambas parcialidades (PSI, 2008). Y, tal y como ya se ha señalado a partir de los registros del Padrón General de Usuarios de la Comunidad de Yanque (2013), dicha constante sigue prevaleciendo en la actualidad.

Se puede afirmar, entonces, que una minoría de familias yanqueñas son mayoristas, mientras que una mayoría de familias yanqueñas son minoristas, hecho que evidencia que la estratificación socio-económica a partir de la tenencia de tierras del siglo XVI es todavía vigente en el siglo XXI, aunque las familias mistis (los Rivera, Málaga y Huerta) detentaron el control político, económico y territorial del distrito desde finales del siglo XIX hasta la segunda década de la 
mitad del siglo XX (Benavides, 1988; Manrique, 1986, 1991 y 2001), dejaron de ser progresivamente las mismas familias, a partir de la Ley de Reforma Agraria (1969), que en la actualidad concentran (los Checa, Huaracha, Inca, Llaza, Mamani, Rivera y Vilcazán) la mayor cantidad de tierras agrícolas de Yanque. $Y$ aunque los Rivera de hoy son parientes consanguíneos de los mistis, del mismo apellido, de los siglos XIX-XX, no ejercen, en la actualidad, abusos del poder, como sus antepasados. No obstante, sí son un familia que destaca en Yanque - al igual que los Checa, Huaracha, Inca, Llaza, Mamani y Vilcazán - por sus posicionamiento económico, político y/o religioso en la comunidad.

Así, pues, los datos etnohistóricos y antropológicos, pasados y presentes, reafirman la existencia de una marcada distribución inequitativa de las riquezas, hecho que ha ocasionado y ocasiona, hasta la actualidad, tensiones y conflictos por el control al interior de la comunidad.

\subsection{Ucños mañay yaku: identidad mitoló- gica y estrategia política}

La marcación de la diferencia entre las identidades intercomunales constituye también un elemento importante para ubicar a Yanque y a los yanqueños dentro del valle del Colca. Un fin de semana de julio de 2015, durante la fiesta patronal en honor al apóstol Santiago, en el distrito de Coporaque, a treinta minutos en automóvil desde Yanque, un hombre de la orquesta, al ver a yanqueños en medio del baile de los turcos, la comida y la bebida de la plaza, dijo por el altoparlante: "¡Aquí hay gente de Yanque! ¡Qué salgan a bailar esos ucños!". A los yanqueños se les denomina ucños porque se les percibe como humildes y benevolentes, en apariencia, pero traicioneros, en el fondo. Porque robaron el agua de otros distritos. Otra denominación interdistrital que también se utiliza para referirse a los yanqueños es mañay yaku, haciendo alusión al agua prestada. Pero, hay que comprender que ambos términos quechua se encuentran teñidos de dichas connotaciones a raíz de los conflictos y las rivalidades por la propiedad y el acceso entre las comunidades de Yanque Hurinsaya y Coporaque, por las aguas del Mismi, que datan desde 1890 , y pasan por la existencia de los documentos de 1897 y 1925, hasta la batalla interdistrital en Chachayllo, en 1971, finalizando con el fallo favorable para Yanque Hurinsaya, en 1972, a partir de la victoria motivada por la muerte de uno de sus miembros a causa de la piedra lanzada por la waraka de un coporaqueño (Benavides, 1998). Por eso, desde ese entonces, en Chachayllo, se realizan rituales en conmemoración a la muerte de Jesús Montalvo Suni.

La importancia de la agrícultura de la comunidad de Yanque no solo se manifiesta a nivel ritual, sino también a nivel mitológico. En la comunidad de Yanque, González Aguilar (2016) ha encontrado que ciertos mitos agrícolas se usan como estrategias narrativas para legitimar el derecho de acceso al agua, e incluso como argumentos legales, si recordamos que los comuneros de la parcialidad de Yanque Hurinsaya apelaron al usufructo milenario que habrían hecho sus antepasados sobre las aguas del Mismi, que se encuentra dentro de la jurisprudencia territorial de la comunidad de Coporaque, para obtener el reconocimiento del Estado para la administración y gestión comunal de este bien hídrico.

Valderrama y Escalante (1988) observaban que la comunidad de Yanque es - como otras 
del valle del Colca y de los Andes - una sociedad hidráulica; es decir, es una sociedad que se organiza colectivamente en torno al agua, la tierra y las montañas. Estas condiciones materiales de producción (la agricultura como una actividad de subsistencia) son las bases infraestructurales de instituciones superestructurales (los mitos y los rituales en torno al agua, la tierra y las montañas). Así, Valderrama y Escalante (1997) encuentran varios mitos yanqueños etiológicos que inciden en la importancia social del agua, entre los que se cuentan el relato del Inca Maita Ccápac en el Valle del Colca, donde se narra cómo el rechazo al inca por parte de los yanqueños de entonces le costó a la comunidad un acceso limitado al recurso hidráulico; o el relato del Origen de las aguas de Hanansaya Yanque, donde se narra cómo el cacique Juan Gualberto Choquehuanca de Yanque Hanansaya llevó, ayudado por mil hombres, el agua del cerro Waranqanti a dicha parcialidad a pedido de la princesa Sumaq Huayta, a quien había desposado para vivir en esta comunidad que hasta ese entonces carecía del recurso hidráulico (aunque existe otra versión yanqueña de este mito, donde es el kuraka Usqay Maqta de Yanque Hanansaya quien desposa a la princesa Sumaq Huayta, y donde esta es hija del cacique Juan Gualberto Choquehuanca. Pero, como en la primera versión de este mito, el agua del cerro Waranqanti es llevada, por mil hombres, a Yanque Hanansaya, a pedido y como condición de la princesa para casarse y vivir en esta parcialidad, que, a partir de ese entonces, obtuvo el acceso al agua).

Actualmente, ambos mitos son usados por los comuneros de Yanque Hanansaya, a raíz de los conflictos y las rivalidades por la propiedad y el acceso entre dicha parcialidad y Chivay por las aguas del nevado Waranqanti, para reafirmar, como los yanqueños de Hurinsaya, sus derechos de usufructo de agua reconocidos legalmente por el Estado en el siglo XX. En el año 2014, durante el último día del Yarqa Aspiy, pudimos recoger una versión diferente de ambos mitos narrados por faenantes de Yanque Hanansaya. Mientras descendíamos de la montaña, siguiendo los pasos de la banda de música y de la jerarquía política hacia la plaza del pueblo, abrazados en la oscuridad de la noche y un poco embriagados por la chicha de maíz y cebada que se había helado con el intempestivo descenso de temperatura, ellos dijeron: “¿Ves esa montaña? Es Waranqanti. El Inca trajo sus aguas para acá y se casó con una yanqueña. El Inca nos dejó esas aguas. Se las quitó a Chivay y nos las dio a nosotros" (Édgar Tinta, 46 años).

Por último, hay familias que tienen un mayor acceso al manejo del poder político en la comunidad. En Yanque, varios relatos mitológicos del distrito (Cook, 2011; Pease, 2014; Valderrama y Escalante, 1997) revelan el posicionamiento histórico de las familias de élite, como los Choquehuanca de Hanansaya (el cacique de la parcialidad de Hanansaya que hizo que construyeran el canal que dirigía las aguas del Waranqanti a esta parcialidad se apellidaba Choquehuanca, según Zevallos, 2006) y los Checa de Hurinsaya (el principal curaca prehispánico de la parcialidad de Hurinsaya, como aparece en el censo de 1586, se llamaba García Checa, según Cook, 2011). Por ejemplo, el prestigio ritual que detenta la familia Checa se ve legitimado por el nivel mitológico e histórico. $Y$ es que solamente los hombres de la familia Checa poseen el derecho, reconocido además por la comunidad, de hacer ofrendas en la montaña Mama Umahala (mujer y compañera del Tata 
Mismi, y ubicada a mitad del recorrido), porque fueron tierras de los Aukay Ch'eqa en tiempos prehispánicos (hecho que revela cómo diferentes formas de cargos hereditarios de linaje son nuevas formas de cacicazgos). $Y$ es por eso que, así como el Yaku Alcalde y su Yana son los representantes de la comunidad ante el lado masculino del agua, los Checa son los representantes de la comunidad ante el lado femenino del agua (Valderrama y Escalante, 1988), dependiendo de ambos la realización anual de dicho ritual. Así también podemos ver el prestigio histórico que detenta Gerardo Huaracha, uno de los últimos ganaderos y propietarios de grandes extensiones de terrenos dentro de la comunidad de Yanque. Es uno de los últimos testigos vivos de la batalla de Chachayllo, y es nieto de Félix Huaracha Ríos, el último cacique de la parcialidad de Yanque Hurinsaya. Y también es posible notar el prestigio religioso de las generaciones de Yaku Alcaldes y de Kamachikuq Yanas (especialistas), que actualizan formas y contenidos ceremoniales tradicionales andinos.

\section{Reflexiones finales}

En Yanque, como en otros distritos del valle del Colca, la agricultura es la actividad social central de la comunidad. La agricultura convoca y congrega las dimensiones económicas y políticas de la vida colectiva yanqueña. A lo largo del presente artículo se ha brindado evidencias etnográficas que tratan de mostrar cómo Yanque es una comunidad andina que, en el siglo XXI, continúa preservando la tradición de sus herencias culturales mientras se encuentra inserta en modernos cambios sociales que conllevan los dinámicos proce- sos de interrelación con sociedades urbanas y globales capitalistas. Es cierto también que muchas de estas evidencias predominantemente sugieren una progresiva "desaparición" de lo "andino": a) En la dimensión económica, existe un fuerte desplazamiento de la reciprocidad y de la agricultura por la compra-venta de productos y servicios de una pluriactividad asalariada; así como también existe muy poco interés de las generaciones jóvenes hacia la agricultura en detrimento de las actividades asalariadas; b) En la dimensión política, ha aparecido una nueva figura: la del Presidente de la Comisión de Turismo, que revela la importancia social-productiva de esta actividad asalariada. Pero también recordemos que en Yanque se mantiene aún una fuerte comunalización con respecto a la defensa de sus tierras agrícolas, fuentes de agua de riego y formas de gobierno local.

Tal y como hemos visto, la comunidad de Yanque ha venido teniendo, progresivamente, cada vez más directas relaciones con lo urbano y lo global. Ello ha hecho que su panorama social actual sufra profundas transformaciones, evidentes ya a nivel económico y político. Esta nueva ruralidad que experimenta la comunidad de Yanque trae, ciertamente, nuevas formas de vida, pero, sobre todo, nuevos retos para sus miembros si estos tienen por fin que los elementos de su cultura local no sean desplazados (y no necesariamente desaparecidos), paulatinamente, por las modernas lógicas capitalistas. Quizás todas estas nuevas tensiones y escenarios conlleven también nuevas formas de pensar las comunidades campesinas en los Andes peruanos y su creciente interrelación con las ciudades y el mundo. 


\section{Notas}

1 Aunque los Málaga de hoy son parientes consanguíneos de los mistis, del mismo apellido, de los siglos XIX-XX, no ejercen, en la actualidad, abusos del poder, como sus antepasados. Tampoco destacan en Yanque por su posicionamiento económico, político ni religioso en la comunidad.

2 En el 2015, la UNESCO reconoció el Wititi como patrimonio cultural inmaterial de la humanidad.

\section{Referencias bibliográficas}

Alberti, G. \& Mayer, E. (1974). Reciprocidad e intercambio en Ios Andes peruanos. Lima: IEP.

Arguedas, J. M. (1985). Indios, mestizos y señores. Lima: Horizonte.

Autoridad Nacional del Agua (ANA) (2014). Cuadro de Valores de Retribución Económica. Tarifa por Uso de Infraestructura Hidráulica Menor de la Junta de Usuarios del Valle del Colca, Resolución Administrativa № 006-2013-ANA/ALA.CSCH.

Barrionuevo, A. (1971). El Varayoq. Equilibrador entre dos mundos. Lima: CIBA.

Benavides, M. (1988). "Grupos de poder en el Valle del Colca (Arequipa). Siglos XVI - XX”. En Matos Mendieta, R. (compilador). Sociedad andina: pasado y presente. Contribuciones en homenaje a la memoria de César Fonseca Martel. Lima: FOMCIENCIAS.

(1989). "Las visitas a Yanque Collaguas de los siglos XVI y XVII: organización social y tenencia de tierras". Bulletin IFEA, № 2 . (1998). "Las batallas de Chachayllo: la lucha por el agua en riego en el valle del Colca (Arequipa, Perú)", Espacio y Desarrollo, № 10.

Cook, N. D. (2011). Los hijos del volcán. Dualidad andina en el valle del Colca. Arequipa: El Lector.

Córdova, H. (2003). "Turismo en el valle del Colca y sus impactos en el desarrollo", Espacio y desarrollo, № 15.

Damonte, G. (2000). "Apuntes sobre el teniente gobernador". En Juan Ansión, Alejandro Diez y Luis Mujica (editores). Autoridades en espacios locales: una mirada desde la antropología. Lima: PUCP.

Diez, A. (2001). “Organizaciones e integración en el campo peruano después de las políticas neoliberales". En Norma Giarracca (editor). ¿Una nueva ruralidad en América Latina?, Buenos Aires: CLACSO. (2005). "Los sistemas de cargos religiosos y sus transformaciones". En Manuel Marzal (editor). Religiones campesinas. Madrid: Trotta.

(2012). "Nuevos retos y nuevos recursos para las comunidades campesinas". En Diez, A. (editor). Tensiones y transformaciones en comunidades campesinas. Lima: PUCP.

(2014). "Cambios en la ruralidad y en las estrategias
3 Aunque, de acuerdo con Valderrama y Escalante (1988), existen otros nombres de bautizo para las varas que se encuentran relacionados a fechas centrales del calendario religioso católico: por ejemplo, el 25 de diciembre, se les denomina Manuel (por Jesús); el 01 de enero, se les denomina Silvestre (por San Silvestre); y el 02 de febrero, se les denomina Tomás (por la Virgen de la Candelaria).

de vida en el mundo rural. Una relectura de antiguas y nuevas definiciones". En: Diez, A. (editor). Perú: el problema agrario en debate. Lima: SEPIA.

Echeverría \& Morales, F. (1952) [1804] "Memoria de la Santa Iglesia de Arequipa". En Barriga, V. (editor). Memorias para la Historia de Arequipa. Arequipa.

Fonseca, C. (1988). "Diferenciación campesina en los Andes peruanos". En César Fonseca y Enrique Mayer (editores). Comunidad y producción en la agricultura andina. Lima: FOMCIENCIAS.

Gerencia Regional de Agricultura de Arequipa (GRAA) (2014). Compendio de Campañas Agrícolas (2004-2014). Ejecución y perspectivas de la información agrícola (Yanque, Caylloma, Arequipa).

González, M. (2016). Políticas hídricas y derechos de agua: cambios y continuidades en la organización social del riego en la comunidad de Yanque. Tesis de licenciatura. Lima: PUCP.

Instituto Nacional de Estadística e Informática (INEI) (2011). Compendio Estadístico de la región de Arequipa. Arequipa: Oficina Departamental de Estadística e Informática.

Manrique, N. (1986). Colonialismo y pobreza campesina. Caylloma y el Valle del Colca. Siglos XVI-XX. Lima: DESCO.

(1991). "Gamonalismo, lanas y violencia en los Andes".

En Henrique Urbano (compilador). Poder y violencia en los Andes. Cusco: CBC.

(2001). "Expansión terrateniente y gamonalismo en el sur peruano", Travesía, № 5/6.

Montoya, M. (2013). Turismo Comunitario y desarrollo rural. Interacción y escalamiento de innovaciones. Lima: IEP.

Mujica Barreda, E. \& De la Vera Cruz, P. (2002). "El valle del Colca: un paisaje cultural dinámico en el sur del Perú". En Mujica, E. (editor). Paisajes culturales en los Andes. Lima: UNESCO.

Neira, M. (1961). Los collaguas. Tesis doctoral. Arequipa: Universidad Nacional de San Agustín.

Plaza, O. \& Francke, M. (1981). Formas de dominio, economía y comunidades campesinas. Lima: DESCO.

Pease, F. (editor) (1977). Collaguas I. Lima: PUCP.

Pease, F. (2014). Del Tawantinsuyu a la historia del Perú. 


\section{Lima: PUCP.}

Poma, D. \& Aronés, C. (2011). "Impacto del turismo en el valle del Colca”. En Eduardo Toche (compilador). Ajustes al modelo económico: la promesa de la inclusión. Lima: DESCO.

Programa Subsectorial de Irrigaciones (PSI) (2008). Marco de Planificación para Pueblos Indígenas y Comunidades Campesinas. Lima: Ministerio de Agricultura y Riego.

Ráez, M. (2001). "Jerarquía y autoridad comunal. Los varayos y la Fiesta de Agua de la comunidad campesina de Lachaqui, Canta”. En Cánepa Koch, G. (editora). Identidades representadas. Performance, experiencia y memoria en los Andes. Lima: PUCP.

(2002). En los dominios del cóndor. Fiestas y música tradicional del valle del Colca. Lima: PUCP.

Ramírez León, L. (2014). La vara de mando popular y tradicional en el Perú. Lima: UNMSM.

Robinson, D. J. (editor) (2006). Collaguas III. Yanque Collaguas. Sociedad, economía y población, 1604-1617. Lima: PUCP.

Robles, R. (2008). "Agricultura de riego y tradiciones en el valle del Colca”. Revista de Antropología, № 6.

(2010). "Sistemas de riego y ritualidad andina en el valle del Colca". Revista Española de Antropología Americana, № 1.

Rostworowski, M. (1981). "Mediciones y cómputos en el antiguo Perú", en Heather Lechtman y Ana María Soldi (editores). La tecnología en el mundo andino. Runakunap kawasayninkupaq rurasqankunaqa. Tomo II. Subsistencia y mesuración. México: Universidad Nacional Autónoma de México.

Treacy, J. (1994). Las chacras de Coporaque. Andenería y riego en el Valle del Colca. Lima: IFEA.

Valderrama, R. (2012). Pastores, pastos y rebaños en la provincia de Caylloma (Arequipa). Tesis doctoral. Lima: PUCP.

Valderrama, R. \& Escalante, C. (1997). La doncella sacrificada. Mitos del Valle del Colca. IFEA, Lima.

(1988). Del Tata Mallku a la Mama Pacha. Riego, sociedad y ritos en los Andes peruanos DESCO: Lima.

(1986). "Sistema de riego y organización social en el valle del Colca - Caso Yanque”. Allpanchis, № 27.

Zevallos, M. (2006). Contando nuestra historia. Cuentos, fábulas y leyendas del Valle del Colca contados por niños. Arequipa: Universidad Católica de Santa María. 